Review

\title{
Engineered Aptamers for Enhanced COVID-19 Theranostics
}

\author{
Caleb Acquah, ${ }^{1} \mathrm{Jaison}_{\mathrm{J}} \mathrm{Jevanandam},{ }^{2}$ Kei Xian Tan, ${ }^{3}$ and Michael K. Danquah (i) ${ }^{4}$ \\ ${ }^{1}$ Faculty of Health Sciences, University of Ottawa, Ottawa, ON K1H 8M5, Canada; ${ }^{2}$ CQM-Centro de Química da Madeira, \\ Universidade da Madeira, Campus da Penteada, 9020-105 Funchal, Portugal; ${ }^{3}$ School of Materials Science \& Engineering, \\ Nanyang Technological University, Singapore 639798, Singapore; and ${ }^{4}$ Department of Chemical Engineering, University of \\ Tennessee, Chattanooga, TN 37403, USA
}

(Received 19 October 2020; accepted 8 December 2020; published online 15 January 2021)

Associate Editor Michael R. King oversaw the review of this article.

\begin{abstract}
Introduction - The 2019-novel coronavirus disease (COVID19) is an intractable global health challenge resulting in an aberrant rate of morbidity and mortality worldwide. The mode of entry for SARS-CoV-2 into host cells occurs through clathrin-mediated endocytosis. As part of the efforts to mitigate COVID-19 infections, rapid and accurate detection methods, as well as smart vaccine and drug designs with SARS-CoV-2 targeting capabilities are critically needed. This systematic review aimed to present a good mapping between the structural and functional characteristics of aptamers and their potential applications in COVID-19 theranostics.

Methods - In this study, extensive discussions into the potential development of aptameric systems as robust theranostics for rapid mitigation of the virulent SARS-CoV-2 was made. Information required for this study were extracted from a systematic review of literature in PubMed, SCOPUS, Web of Science (WOS), and other official related reports from reputable organisations.

Results - The global burden of COVID-19 pandemic was discussed including the progress in rapid detection, repurposing of existing antiviral drugs, and development of prophylactic vaccines. Aptamers have highly specific and stable target binding characteristics which can be generated and engineered with less complexity for COVID-19 targeted theranostic applications.

Conclusions-There is an urgent need to develop safe innovative biomedical technologies to mitigate the dire impact of COVID-19 on public health worldwide. Research advances into aptameric systems bode well with the fact that they can be engineered for the development of effective and affordable diagnostics, therapeutics and prophylactic vaccines for SARS-CoV-2 and other infectious pathogens.
\end{abstract}

Keywords-Coronavirus, SARS-CoV-2, COVID-19, Aptamers, Theranostics.

Address correspondence to Michael K. Danquah, Department of Chemical Engineering, University of Tennessee, Chattanooga, TN 37403, USA. Electronic mail: michael-danquah@utc.edu

\section{INTRODUCTION}

Emerging and re-emerging pathogens are a threat to public health with the current pandemic being a wakeup call regarding their virulence and impact on socio-economic activities. These infectious pathogens have resulted in severe outbreaks over several centuries including 1918 H1N1 flu pandemic (Spanish influenza), Severe Acute Respiratory Syndrome (SARS) in 2003, H1N1 influenza pandemic in 2009, Ebola in 2014, Zika virus in the mid-2000s and the mid-2010s, Middle East Respiratory Syndrome (MERS) in 2012, and Vibrio cholerae which is still in circulation. So far, there have been three severe outbreaks in the twentyfirst century resulting in a public health emergency of international concern (PHEIC) that have been traced to coronaviruses (CoVs).

Coronaviruses are enveloped positive single-stranded RNA viruses having the largest genome size among RNA viruses. ${ }^{82}$ They have four structural proteins; spike (S), envelope (E), membrane (M) and nucleocapsid $(\mathrm{N})$ that facilitate interactions with the host cell and activities within the host after internalization. Coronaviruses can cause several illnesses including respiratory tract infections and gastroenteritis. ${ }^{69}$ Notably, RNA viruses have an inherent ability to undergo genetic recombination and mutation to sustain their survival in new hosts. ${ }^{42}$ Additionally, the $S$ proteins on the surface membrane of RNA viruses enable their infectivity in a host.

There are currently seven (7) coronaviruses, namely; SARS-CoV-2, MERS-CoV, SARS-CoV, HCoV-229E, HCoV-OC43, HCoV-NL63 and HCoV-HKU1, known to infect the human population. Until recently, the virulent members of the coronavirus family were severe acute respiratory syndrome (SARS-CoV) and Middle East respiratory syndrome coronavirus 
(MERS-CoV) which resulted in the 2003 and 2010 epidemics, respectively. MERS-CoV affected a minimum of 2494 persons and more than 858 deaths. ${ }^{87}$ Phylogenetic analysis revealed MERS-CoV to have probably originated from Pipistrellus Pipistrellus which are major reservoirs of group $2 \mathrm{c}$ bat coronaviruses. ${ }^{63}$ Similarly, bats have been revealed as the natural reservoir of SARS-CoV with infected civet cats as the intermediate host through which humans became infected. This resulted in at least 8437 infected cases and an estimated 813 fatal cases. ${ }^{88}$ The continuous spread and existence of SARS-CoV amongst the human population were annihilated through effective global public health response coordinated by the World Health Organisation (WHO). However, there are four (4) human coronaviruses $(\mathrm{HCoV})$ that have been circulating in the human population for decades, namely, HCoV-HKU1, HCoV-NL63, HCoV-229E and HCoV-OC43. ${ }^{33,77,85}$ These four virion particles have been documented to cause relatively mild respiratory infections to humans. ${ }^{63}$

At present, of particular concern to the world is the newly emerged SARS-CoV-2 pandemic with more than two million morbidities and at least a twenty percent mortality cases in about 210 countries and territories as of mid-April 2020. ${ }^{91}$ SARS-CoV-2 has proven to be a major threat to public health, social gatherings, and the global economy in a short duration after the first epic centre in the city of Wuhan, China. This is because their transmission occurs rapidly due to factors such as high viral attack rate (about $83 \%$ ), viral shedding by asymptomatic patients and human-tohuman transmission. ${ }^{13}$ Clinical and epidemiological data for COVID-19, howbeit limited, shows a variation in the disease spectrum, reproductive number, and case fatality ratio and infection relative to previous coronavirus diseases. ${ }^{35}$ Furthermore, the structural differences between SARS-CoV-2 and SARS-CoV require that more specific diagnostic and therapeutic techniques are needed for SARS-CoV-2 mitigation programs.

Aptamers are short single-stranded nucleic acids with high specificity and sensitivity to biomolecular or cellular targets. The binding affinity of aptamers to their cognate targets including virion particles is comparable to antibodies, if not superior, ${ }^{98}$ and this is due to the secondary structures of aptamers having a singular function of binding cognate targets. ${ }^{3}$ Aptamers are chemically synthesised and have desirable characteristics such as the absence of batch-to-batch variability, biocompatible, low/no immunogenicity, and easy to engineer for a plethora of enhanced theranostic applications. ${ }^{3,71,80}$ Aptamers have the capacity to distinguish between closely similar molecules including conformational isomers, amino acid mutation, and variation in functional moieties. ${ }^{70,98}$ Therapeutic application of aptameric systems is based on their functionality in acting as (i) antagonist to inhibit protein-protein interactions; (ii) an agonist to stimulate cellular signalling pathways of target receptors; and (ii) carriers for targeted delivery of other therapeutic agents to cells or tissues. ${ }^{36}$ The features possessed by aptamers are ensured through the robust iterative process known as Systematic Evolution of Ligands by Exponential enrichment (SELEX) ${ }^{73}$ summarised in Fig. 1. In this article, an in-depth discussion about the ongoing COVID-19 pandemic situation is presented in relation to its etiology, epidemiological features, and molecular interactions. The article also discusses the advances in rapid aptameric systems and establishes application opportunities for diagnoses, therapeutics, and prophylactic vaccine development.

\section{COVID-19 PANDEMIC}

\section{Etiology and Epidemiology}

On December 31, 2019, the Health Commission of Hubei province, China, made its first announcement of a cluster of unknown viral pneumonia-like cases in some patients mainly in the city of Wuhan. ${ }^{13}$ The cases were later identified to be caused by a novel coronavirus and were provisionally referred to as "2019 novel coronavirus acute respiratory disease (2019nCoV)"; 89 making it the seventh infectious human coronavirus. Subsequently, there were reports from other countries including Taiwan, South Korea, Thailand, Vietnam, Singapore, Japan, Italy, Germany, and the USA with suspected cases. The first epic centre was Wuhan triggering a global public health crisis alert from China with a minimum of 80,000 reported cases. Transmission of COVID-19 across the globe occurred at a horrifying speed resulting in the final declaration of a pandemic by WHO on March 11, 2020. ${ }^{90}$ As of April 22, 2020, the USA had the most clinically reported infected cases which could be due to any or a combination of factors such as the large population size, large volumes of international travels, and high rate of testing recorded in the country. However, the most affected country per 100,000 population size had been San Marino in Europe as of April 22, 2020.

On February 11, 2020, the 2019-nCoV infected disease was renamed as coronavirus disease 2019 (COVID-19) by WHO to distinguish it from other SARS-like diseases. ${ }^{86}$ On the same day, the causative pathogen was formally named as SARS-CoV-2 upon 


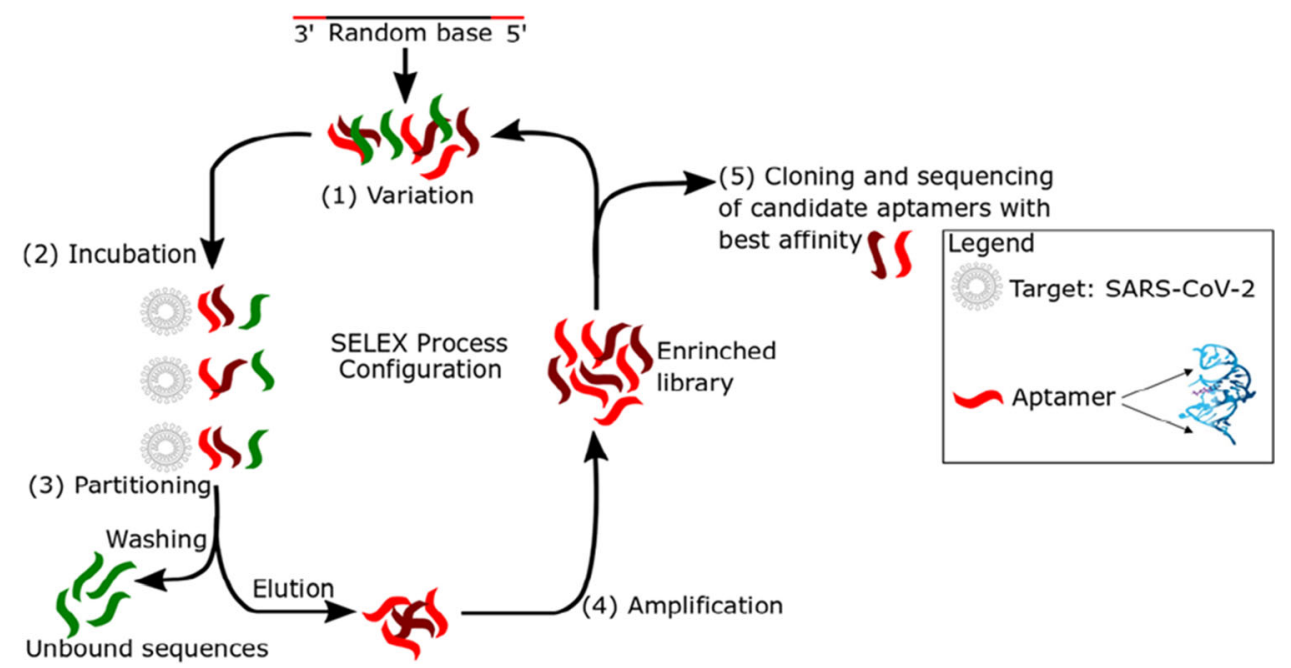

FIGURE 1. Schematic description of Systematic Evolution of Ligands by Exponential enrichment (SELEX) technology in the generation of anti-SARS-CoV-2 aptamers.

standard assessment by the Coronaviridae Study Group (CSG) of the International Committee on Taxonomy of Viruses (ICTV). ${ }^{31}$ Furthermore, phylogenetic analysis of SARS-CoV-2 resulted in it being classified as subfamily Orthocoronavirinae, subgenus Sarbecovirus of the genus Betacoronavirus. ${ }^{99}$

Scientists in China isolated the virus from bronchoalveolar lavage fluid samples of patients and made available the partial and whole genomes of the novel coronavirus on January 7, 2020. ${ }^{55}$ This enabled the rapid development of point-of-care (POC) real-time polymerase chain reaction (RT-PCR) diagnostic assays which are highly specific for coronaviruses. The researchers noticed the genome sequence of SARS-CoV-2 were genetically distinct to the previous coronavirus outbreaks; SARS-CoV $(\sim 79 \%)$ and MERS-CoV $(\sim 50 \%)$. Furthermore, the genome sequence was $88 \%$ genetically identical to two bats obtained SARS-like coronaviruses, namely; bat-SL-CoVZC45 and bat-SL-CoVZXC21. ${ }^{55}$ However, there was a relatively long branch length between the identified SARS-CoV-2 and its closest relatives (bat-SL-CoVZC45 and bat-SL-CoVZXC21); negating them as direct ancestors to SARS-CoV-2. The phylogenetic analysis implicated the presence of an intermediate host between the bat natural reservoir for SARS-CoV-2 and humans as the terminal host.

To address this gap some researchers utilised relative synonymous codon usage (RSCU) bias to study the natural evolution of SARS-CoV-2 and their hosts, and suggested snakes as intermediates and/or hosts before infecting humans. ${ }^{39}$ Nevertheless, the bioinformatics technique and fundamental biological assumptions utilised were limited in scope. For instance, their analyses involved less than $2 \%$ of all protein-coding genes in a typical snake genome, and this can affect the accuracy of the RSCU statistics. Also, the Codon Usage Database utilised by the research group was out of date. Besides, only 8 vertebrates out of more than 100000 vertebrates were incorporated in the analyses. That notwithstanding, preliminary evidence from metagenomic sequencing indicates a strong homology to sequence reads of bat coronaviruses RaTG13, pangolin coronaviruses, and SARS-CoV-2. ${ }^{79,96}$ There was as much as $97.4 \%$ amino acid similarity between the receptor-binding domain of S protein of Pangolin coronaviruses and the receptor-binding domain of SARS-CoV-2, whiles the remaining part of the whole genome of SARS-CoV-2 was very similar $(96 \%)$ to bat coronavirus RaTG13. This indicates the possible occurrence of a selectively mediated convergent evolution between bat coronaviruses RaTG13 and pangolin coronaviruses to form SARS-CoV-2.

\section{Pathogenicity}

Transmission of the virus occurs through infected aerosols and fomites. SARS-CoV-2 specifically binds to the functional surface receptors, angiotensin-converting enzyme 2 (ACE2), similar to SARS-CoV but different from MERS-CoV which binds to CD26 (also known as dipeptidyl peptidase 4, DPP4) receptors. ${ }^{62}$ The binding interaction between the spike protein (S) of SARS-CoV2 and ACE2 receptors mediates viral attachment to host cells which consequently leads to infection. Upon infection, SARS-CoV-2 impairs the ciliated epithelial cells of the upper and lower respiratory tract, reducing its ability to handle foreign particles.

The recommended incubation period for symptoms of COVID-19 to be obvious is fourteen (14) days. Accurate incubation duration is needed to meaning- 
fully inform public health decisions such as active monitoring, surveillance, control, and modelling. ${ }^{44}$ Notable symptoms of COVID-19 include fever, dry cough, dyspnoea, and diarrhoea. ${ }^{35}$ Also, chest radiographs of critically ill patients infected with the virus show invasive lesions in both lungs. ${ }^{13}$ SARS-CoV-2 is highly transmissible with an attack rate as high as $83 \%{ }^{13}$ Preliminary evidence suggests that people with underlying health conditions, older patients, and racial minorities (such as Latinos, African Americans, and Native Americans) are high-risk groups to the severity of COVID-19. ${ }^{40}$ There have also been confirmed reports about reverse zoonotic COVID-19 transmission to a tiger in a zoo which has triggered concerns about possible spread by domestic pets. ${ }^{7}$ Nevertheless, at present, no significant evidence suggests that humans are at risk of being infected with SARS-CoV-2 from domestic animals. The stability kinetics of SARS-CoV2 virion particles are similar to SARS-CoV. ${ }^{76}$ It was observed that depending on the inoculum shed, SARSCoV-2 could stay viable in aerosols for about $3 \mathrm{~h}$; copper, $4 \mathrm{~h}$; cardboards, $4 \mathrm{~h}$; stainless steel, $5.6 \mathrm{~h}$; and plastics $6.8 \mathrm{~h}$. The similarity in stability kinetics between SARS-CoV and SARS-CoV-2 shows that their epidemiological differences could be due to other factors such as a high viral load in the upper respiratory tract and viral shedding by pre-symptomatic and asymptomatic SARS-CoV-2 infected persons. ${ }^{76,28}$

\section{STRUCTURE OF SARS-COV-2}

A SARS-CoV-2 virion consists of a single-stranded (ss) RNA with nucleoproteins that are enveloped by a spherical or pleomorphic capsid with a membrane protein. The capsid envelope contains club-shaped projections of glycoproteins called spike glycoproteins, which gives them a crown shape on the outer surface, and hence the name 'corona' virus. ${ }^{19}$ These viruses possess a large genome sequence of $26.4-31.7 \mathrm{~kb}$, compared to other RNA viruses with 32 to $43 \%$ of guanine + cytosine $(\mathrm{G}+\mathrm{C})$ content. $^{8}$ Further, the viruses contain several small open reading frames (ORFs) as their conserved genes in their spike, membrane, ORF1ab, envelope and nucleocapsid and narrow down to their nucleocapsid gene in distinct lineages of coronavirus. It is noteworthy that the fragment in the $\mathrm{N}$-terminal present in the spike protein is specific only to coronavirus. Coronaviruses possess genes that can encode for their structural proteins (S, E, $\mathrm{M}$ and $\mathrm{N}$ ) in their $5^{\prime}-3^{\prime}$ terminal end ${ }^{84}$ Furthermore, coronaviruses contain a genome with at least six ORFs, in which two-thirds of the total genome length encodes 16 non-structural proteins (nsps). A frameshift is present in between ORF1a and ORF1b to yield ppla and pplab polypeptides. The viral encodes for main protease (Mpro) or chymotrypsin-like protease (3CLpro) and few papain-like proteases by processing those polypeptides into 16 nsps. In addition, all the core structural proteins are encoded near the $3^{\prime}$ terminal by the ORFs 10 and $11{ }^{84}$ Besides, SARS-CoV-2 contains special mature accessory proteins called hemagglutinin-esterase, $3 \mathrm{a} / \mathrm{b}$ and $4 \mathrm{a} / \mathrm{b}$ protein, which are essential for performing significant functions in viruses such as maintenance and replication. ${ }^{75}$

The phylogenetic study of SARS-CoV, MERS$\mathrm{CoV}$, and SARS-CoV-2 showed that the presence of the untranslated region in the $5^{\prime}$ and $3^{\prime}$ terminal end helps in the interactions with inter- and intramolecular compounds. Thus, these regions are highly significant in the functional interactions between RNAs and are essential for cellular and viral proteins binding process. ${ }^{94}$ In SARS-CoV-2, the non-structural proteins have a size of $29844 \mathrm{bp}$ and are encoded by Pblab at $5^{\prime}$ terminal end as the ORF present in the total genome length. However, the size of the non-structural proteins of MERS-CoV and SARS-CoV is $30119 \mathrm{bp}$ and $29751 \mathrm{bp}$, respectively. Comparison of the spike protein in the $3^{\prime}$ terminal between the three betacoronaviruses (SARS-CoV-2, SARS-CoV, and MERS-CoV) shows a significant difference in their 1273 aa, 21493 aa, and 1270 aa. In March 2020, the Global Initiative on Sharing All Influenza Data (GISAID) reported 253 genome sequences (both complete and partial) of SARS-CoV-2 that have been contributed and analyzed by various researchers across the globe since December 2019. The genome sequence is essential to understand the evolution of the virus within humans, assist in tracing the infection pathway, and design strategies for prevention.

\section{STRUCTURAL PROTEINS OF SARS-COV-2}

The structure of SARS-CoV-2 is presented in Fig. 2a showing the various structural proteins $(\mathrm{S}, \mathrm{M}$, $\mathrm{E}$ and $\mathrm{N}$ ). The spike proteins of SARS-CoV-2 are made up of $\mathrm{S}$ protein trimers that belong to the class 1 group of viral glycoprotein fusions such as Influenza hemagglutinin, Ebola virus glycoprotein, Human immunodeficiency virus (HIV) glycoprotein 160, and paramyxovirus $\mathrm{F}^{25}$ The $\mathrm{S}$ protein is reported to contain a single peptide of 1-12 amino acid in the $\mathrm{N}$ terminal, an extracellular domain of 13-1195 amino acids, a transmembrane domain of 1196-1215 amino acids, and an intracellular domain of 1216-1255 amino acids. ${ }^{21}$ The $\mathrm{S}$ protein is critical in these viruses as it is responsible for its ability to bind with human cells via angiotensin-converting enzyme 2 (ACE2). ${ }^{47}$ Likewise, $\mathrm{M}$ protein which is another significant protein com- 


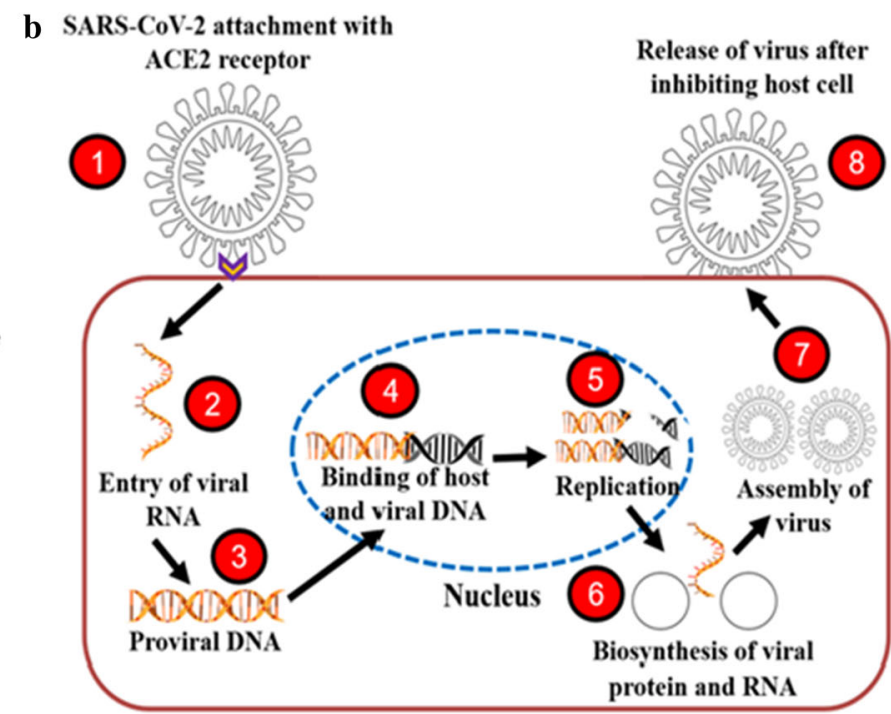

FIGURE 2. (a) Structure of SARS-CoV-2 illustrating the various structural proteins (S, M, E and N). (b) Stages of SARS-CoV-2 replication in host cells. The S proteins of SARS-CoV-2 enable attachment to host ACE2 receptors. The M proteins are essential in shaping of the virions, influencing membrane curvature, and attachment to the nucleocapsid. The E protein is responsible for virus assembly and release, as well as pathogenesis. The $\mathrm{N}$ proteins are repressors of RNA interference and antagonist of interferon. The $\mathrm{N}$ proteins attaches to nsp3 proteins to connect the genome to the replication-transcription complex. They also transform the encapsidated genome into virions.

ponent in the envelope of the coronavirus family interacts with a human host via heparan sulfate proteoglycans. ${ }^{59}$ Perrier et al. revealed via subcellular localization analysis that the $\mathrm{M}$ protein of the coronavirus family possesses the ability to retain in the intracellular region of the trans-Golgi network and identified two motifs in the distal C-terminal domain part as the basic requirement for specific localization. ${ }^{61}$ Furthermore, the interaction between $\mathrm{S}$ and $\mathrm{M}$ proteins is necessary to retain $\mathrm{S}$ protein in the intermediate compartment of the endoplasmic reticulum and the Golgi complex to incorporate a coronavirus into a host. ${ }^{24}$ Similarly, membrane and nucleoprotein bond formation stabilizes the nucleoprotein-RNA complex and the internal viral core and eventually promotes viral assembly completion. ${ }^{58}$ Besides, it has been demonstrated that the viroporins such as $\mathrm{E}$ proteins in the coronavirus family are considered as integral membrane proteins with enhanced ion channel activity. ${ }^{66}$ Moreover, Westerbeck and Machamer (2019) revealed that the single hydrophobic domain of the $\mathrm{E}$ protein in coronaviruses targets the Golgi membranes through in vitro cation channel activity and alters its $\mathrm{pH}$ for spike protein protection to promote infectious virus release. ${ }^{83}$ Nucleoprotein is a multifunctional protein with the genome encapsulation ability through capsid that can disrupt innate immunity, replicate during the synthesis of RNA, and shuts off translation processes in the host. It is a $40 \mathrm{kDa}$ sized protein with twofold $\mathrm{N}$ and $\mathrm{C}$ terminal domains, which are separated by a disordered LKR region with a stretch of serine or arginine to regulate the $\mathrm{N}$ protein function during phosphorylation. ${ }^{56,78}$ Figure $2 \mathrm{~b}$ is the schematic representation of SARS-CoV-2 replication, after internalization into human host cells using the $S$ proteins. Together, SARS-CoV-2 proteins are critical to the successful development of drugs and vaccines for COVID-19 due to their role in viral assembly and replication.

\section{ENGINEERING APTAMERS FOR RAPID DETECTION OF COVID-19}

Current detection of SARS-CoV-2 is based on realtime polymerase chain techniques (RT-PCR) and antibody assays. RT-PCR is the reference standard as they are highly specific for the detection of the viral RNA genome of SARS-CoV-2 but fraught with challenges such as sample preparations and long residence times. Also, the detection of viral genomes by the RTPCR technique does not necessarily indicate the presence of an infectious virus, especially for patients with strong immune system that have recovered. On the other hand, serologic assays such as enzyme linked immunosorbent assays (ELISA) which are also highly specific have been developed by numerous research institutes and companies for the detection of $\mathrm{S}$ and $\mathrm{N}$ protein antibodies in the serum or plasm of COVID-19 patients. ${ }^{32}$ However, it takes days or even weeks for antibodies (anti-SARS-CoV-2-IgM and $\operatorname{IgG}$ ) to be produced by the immune system of COVID-19 patients 


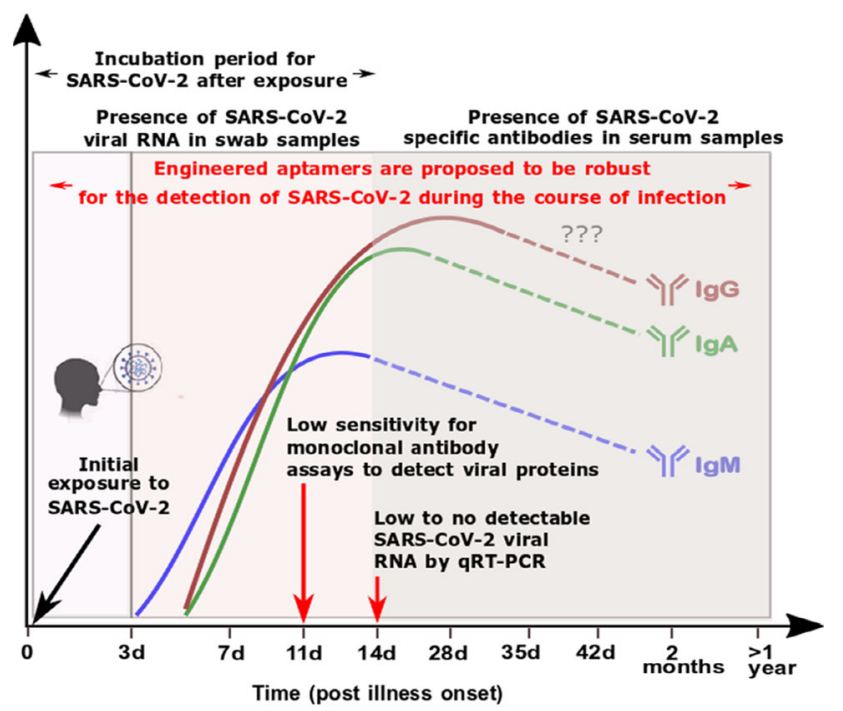

FIGURE 3. Pictorial illustration of window period for efficient detection of viral RNA using RT-PCR and antibodies using serological assays. Figure adapted from Lee et al. ${ }^{46}$

and detected with the serological test, as shown in Fig. $3{ }^{46}$ To circumvent the setbacks in serological assays, monoclonal antibodies that can directly bind unto SARS-CoV-2 proteins can be used in the development of an immunoassay. The $\mathrm{S}$ and $\mathrm{N}$ proteins are useful markers for detection as they are the most exposed and most abundant proteins, respectively. In a recent in vitro experiment, Wang et al., identified monoclonal antibodies, human 47D11 antibody, that can block the conserved epitopes of S proteins of both SARS-CoV and SARS-CoV-2. ${ }^{81}$ Conspicuously, the pathogenesis of SARS-CoV-2 is similar to SARS$\mathrm{CoV} .{ }^{46}$ However, it is expensive to produce monoclonal antibodies. Also, there are ethical issues, susceptibility of contamination for its hybridoma cultures, and lower sensitivity after about 11 days pio., ${ }^{3,43}$ Hence, there is a need to establish highly sensitive and specific assays that can be robust during the course of infection in order to improve diagnosis and prognosis of cases related to COVID- 19 .

Aptamers offer greater flexibility in the design of aptasensors for early detection of SARS-CoV-2 in symptomatic and asymptomatic persons, and achieve the ASSURED (Affordable, Sensitive, Specific, Userfriendly, Rapid and robust, Equipment-free, and Deliverable to the end user) diagnostic criteria recommended by WHO. This is due to the biostability, bioavailability, low cost of synthesis, ease of modification, high specificity and sensitivity, and chemical and thermal stability of aptamers as compared to antibodies. ${ }^{3,70}$ Although there is currently no aptamerbased diagnostic technology for the novel SARS-CoV2 virus, the applicability of aptamers has been demonstrated in various diagnostic assays for viral proteins and enzymatic processes analogous to that of SARS-CoV-2 proteins. For instance, Cho et al., generated ssDNA aptamers that detects the $\mathrm{N}$ protein of SARS-CoV with a binding affinity $\left(\mathrm{K}_{\mathrm{d}}\right)$ of $4.93 \pm 0.30 \mathrm{nM} .{ }^{14}$ Roh \& Jo, (2011) developed quantum dots-conjugated RNA aptamer on chip for rapid detection of the $\mathrm{N}$ protein of SARS-CoV. ${ }^{64}$ The aptasensor could detect concentrations as low as $0.1 \mathrm{pg} \mathrm{mL^{-1 }}$. Quantum dots are colloidal nanoparticles of semiconductor materials with optical characteristics comparable with organic fluorophores. Ahn et al., synthesised RNA aptamers and developed an aptasensor that utilised a hybrid of chemiluminescence immunosorbent assay and a nanoarray aptamer chip to detect SARS-CoV. ${ }^{5}$ The synthesised aptamer molecularly recognised the $\mathrm{C}$-terminal region of SARS-CoV $\mathrm{N}$ protein at a concentration as low as $2 \mathrm{pg} / \mathrm{ml}$.

Aptamers, by virtue of the iterative SELEX technique, have the capacity to easily differentiate between targets that are similar, a characteristic that is essential for different viral species or strains of the same family with high coefficient of genome similarity. For instance, Gopinath \& Kumar, (2013) generated RNA aptamers, D-26, with high specificity $\left(\mathrm{K}_{\mathrm{d}}=0.15 \mathrm{pM}\right)$ towards HA protein of a recent pandemic influenza virus strain, pdmH1N1 (A/California/07/2009), from other subtypes of influenza A viruses such as $\mathrm{H} 5 \mathrm{~N} 1 /$ Vietnam, H2N2/Japan, H9N1/Hong Kong, H3N2/ Panama, H7N7/Netherlands, H1N1 (A/New Caledonia/20/1999), and H1N1 (A/Brevig Mission/1918). Also, chemical modification of the D-26 aptamer with 2 -fluoropyrimidines enhanced the biostability against endoribonuclease and binding affinity to $67 \mathrm{fM} .{ }^{30} \mathrm{On}$ the other hand, aptamers can also be engineered to molecularly recognise viral strains that are closely related. Bhardwaj, Chaudhary, Kim, \& Jang (2019) recently generated ssDNA aptamers, V46, that have the capacity to detect different strains of $\mathrm{H} 1 \mathrm{~N} 1$ virus with a high affinity. The binding potency as an aptasensor was evaluated using a label-free electrochemical aptasensor. The significance of their study was to enable easy subtyping of a broad range of $\mathrm{H} 1 \mathrm{~N} 1$ viruses with the same aptasensor and allow for the generation of reliable results even when the virus undergoes antigenic shift. ${ }^{10}$ Thus, various modalities of aptamers can be easily engineered for different molecular recognition applications as there is a need to develop simple and robust point-of-care aptasensors for rapid detection of COVID-19 patients. Due to the chemical synthesis process used for the generation and production of aptamers, they are 10-50 times cheaper than the production of antibodies. ${ }^{54}$ Examples of aptamerbased point-of-care platforms reported in the extant 
TABLE 1. Aptamer-based point-of-care devices for rapid, affordable, sensitive and specific detection of cognate molecules.

\begin{tabular}{|c|c|c|}
\hline Point-of-care assays & Remarks & Reference \\
\hline Smartphone & Detection of Zika virus & 20 \\
\hline Smartphone & $\begin{array}{l}\text { Similar platform for rapid detection of Zika virus is being adapted for } \\
\text { COVID-19 by researchers in University of Utah }\end{array}$ & 23 \\
\hline Aptamer-linked immunosorbent assay (ALISA) & Detection of active Mycobacterium tuberculosis from sputum samples & 65 \\
\hline Aptamer-linked immunosorbent assay (ALISA) & Detection of Mycobacteria tuberculosis in serum and sputum samples & 72 \\
\hline $\begin{array}{l}\text { Aptamer-magnetic bead-electrochemiluminescence } \\
(\mathrm{ECL}) \text { assay }\end{array}$ & Detection of brain natriuretic peptide in serum samples & 11 \\
\hline Dot-blotting & Detection of vaccinia virus & 60 \\
\hline Gold nanoparticle (GNP) aggregation assay & Detection of Staphylococcal enterotoxin B & 53 \\
\hline Upconverting phosphors/nanoparticles (UCNP) assay & Detection of Salmonella typhimurium and Staphylococcus aureus & 22 \\
\hline Lateral flow assay & Detection of thrombin in human plasma samples & 92 \\
\hline Lateral flow assay & Detection of cortisol & 17 \\
\hline Lateral flow assay & Detection of dopamine in urine & 18 \\
\hline Lateral flow assay & Detection of nervous necrosis virus & 51 \\
\hline
\end{tabular}

literature is shown in Table 1 and can be easily adapted for COVID-19.

\section{ENGINEERING APTAMERS FOR COVID-19 THERAPEUTIC APPLICATIONS}

Using an in vitro SELEX method Jang et al. generated an ES15 RNA aptamer that inhibits SARS-CoV non-structural protein 10 (nsP10) with NTPase/Helicase enzymatic activity. ${ }^{37}$ Inhibiting the enzymatic activities of helicases is critical in the development of promising drugs due to their indispensable role in viral genome replication, transcription, and translation. ${ }^{57}$ The ES15 RNA aptamer inhibited dsDNA unwinding activity of the helicase by up to $\sim 85 \%$ in a dose dependent faction with an $\mathrm{IC}_{50}$ of $1.2 \mathrm{nM}$. Shum and Tanner (2008) generated DNA aptamers targeting the helicase of SARS-CoV. The aptamers were found to have two unique secondary structures, G-quadruplex and non-G-quadruplex, which were able to molecularly recognise SARS-CoV helicase and stimulated ATPase activity. ${ }^{68}$ However, only DNA aptamers NG1, NG3 and NG8 with non-G-quadruplex structure were found to inhibit the helicase activity of the coronavirus with $\mathrm{IC}_{50}$ values of $87.7,120.8$, and $91.0 \mathrm{nM}$, respectively. Furthermore, the inhibition activity and biostability was significantly enhanced upon modification of the $3^{\prime}$-end with biotin or inverted thymidine.

On another note, inhibition of viral replication with the use of aptamers have also been demonstrated against diverse viral targets. Similar to other viruses such as HCV and influenza viruses, SARS-CoV-1 and SARS-CoV-2 utilise RNA-dependent RNA polymerase (RdRPs) to catalyze the replication of RNA from an RNA template. RdRPs are encoded in the genomes of all RNA viruses that are void of a DNA stage. $^{26}$ The ability to use aptamers to block RdRPs and inhibit virus replication as anti-viral treatments have previously been demonstrated for $\mathrm{HCV} ., 45$ Blocking RdRPs with aptameric systems as a treatment process for COVID-19 can be another significant step in ensuring recovering of patients. Yamamoto et al. synthesised a 37-mer RNA that specifically binds to the Tat protein or peptides of HIV and prevented in vitro and in vivo Tat-dependent trans-activation. ${ }^{93}$ Gao et al. generated ssDNA aptamers that inhibited NS2 enzymatic activity of HCV by binding to its Nterminal region. NS2 proteins are vital in the viral RNA replication of $\mathrm{HCV}$, influenza viruses, and coronaviruses. ${ }^{27,29}$ It was also observed that the inhibition activity of the ssDNA aptamer did not present any cytotoxic effect in vitro. ${ }^{27}$ Other methods through which aptamers can be engineered for enhanced therapeutic outcomes for COVID-19 include attaching RNA interference genes and biocompatible polymers, as discussed in the section below.

\section{Aptamer-siRNA/miRNA Conjugates}

Targeted therapy using engineered aptamers and RNA interference (RNAi) molecules such as microRNA (miRNA) and small interfering RNA (siRNA) have been shown to be promising in inhibiting virus gene function in the host by cleaving targeted mRNA molecules of the virus. siRNA is short in length with about $21-23$ base pairs and widely used as an exogenous agent for the manipulation of gene expression. ${ }^{4}$ Gene silencing by siRNA shows various potencies in treating cancer metastasis and virus infections. However, there are challenges such as short circulation halflife, targeted delivery, and low cellular uptake that 
have impacted its practical applications in medicines. Also, Cui et al. revealed that the nucleocapsid proteins of coronaviruses have the potential of encoding viral suppressors of RNA Silencing, via its double-stranded RNA binding activity, which facilitates their replication. ${ }^{15}$ Despite these challenges, siRNAs (such as siRNA-M1, siRNA-M2, SARSi-1, SARSi-2, SARSi-3, SARSi-4, SARSi-5, SARSi-6, SARSi-7, SARSi-8, SARSi-9, SARSi-10, SARSi-11, siSC2 and siSC5) have been successfully developed and tested in either in vitro or in vivo setups for prophylactic and/or therapeutic treatment of coronaviruses by targeting the mRNA of the M, N, S or E proteins. ${ }^{48,52}$ Effective use of siRNAs for antiviral treatment requires that: i) it is geared towards a homogenous sequence region of the virus critical for viral replication, ii) there is targeted delivery of the siRNA to the cytoplasmic site of action expressing the viral mRNA, and iii) the siRNA has a high sequence specificity in order to prevent nonspecific target effects or stimulation of the TLR7 or cytokines of the host. ${ }^{67}$ Hence, it is ideal to conjugate siRNA with other vehicular molecules such as aptamers to enhance its specificity as demonstrated by Zhou et al. for HIV-1 treatment. ${ }^{97}$ The researchers reported that aside transport of the functional siRNA to the infected cell the aptamer could also neutralize the virus infection.

MicroRNAs (miRNAs) are endogenous short, double-stranded, and non-coding RNAs that act as regulators for the expression of various genes. A previous study demonstrated the efficacies of an anti-B cell maturation antigen (BCMA) RNA aptamer called apt69.T in treating myeloma when conjugated to miRNA-137 and anti-miRNA-222. The apt69.T-miRNAs conjugates significantly inhibited the NF-kB pathway with reduced cell viability and delivered therapeutics effectively to the targeted BCM-overexpressed myeloma cells. ${ }^{12}$ Also, an AS1411 (aptNCL) DNA aptamer-miRNA let-7d conjugate was synthesized as a novel miRNA anti-cancer therapeutic agent to treat gastric cancer cells. The findings indicated miRNA let-7d as an effective tumour suppressor which was successfully delivered for cellular uptake by targeted nucleolin-positive MKN-45 malignant cells with strong antiproliferative effects. This is attributed to the specific binding affinity of aptNCL aptamer against the overexpressed nucleolin biomarkers. ${ }^{16}$ The synergetic effects between aptamer and miRNA have led to better therapeutic efficacies. Notably, the chemistries demonstrated in the extant literature for the attachment of aptamers to RNAi molecules can be adapted for any transgene of interest. The occurrence of three severe global public health emergencies related to coronaviruses necessitates the need to engineer siR-
NAs and miRNAs with aptamers for targeted treatment.

\section{Aptamer-Nanoparticle (NPS) Conjugates}

Aptamer-NPs conjugates have been studied extensively in delivering an effective dosage of drugs to the targeted active sites for enhanced therapeutic effects. Biocompatible polymers with tuneable properties are often conjugated with aptamer-mediated delivery formulation as aptamer-conjugated biopolymeric micro/nanoparticles to overcome the limitations of aptamers whilst enhancing their targeting capabilities. The effectiveness of ARC1779 PEGylated DNA aptamer was reported in impeding thromboembolism by targeting and blocking the activity of von Willebrand factor in order to inhibit both platelet activation and aggregation. ${ }^{49}$ An EpCAM aptamer-conjugated curcumin-loaded poly(lactic-co-glycolic acid)(PLGA)-lecithin-Polyethylene Glycol (PEG) NP demonstrated high efficacies in targeted delivery of encapsulated drugs to the targeted HT29 colon cancer cells for colorectal adenocarcinoma treatment. Both the encapsulation efficiency and in vivo bioavailability of encapsulated curcumin were significantly improved as compared to the unformulated free curcumin. ${ }^{49}$ Another study also showed the efficacy of RNA aptamerconjugated PEG-PLGA polymeric NPs in the loading and delivery of doxorubicin drug molecules to the targeted MCF-7 breast tumour cells with higher drug encapsulation efficiency, cellular internalization and cytotoxicity for breast cancer treatment. ${ }^{6}$ These aptamer-navigated NPs were shown to offer better targeting affinity, prolong circulation half-life of encapsulated drug molecules and enhance the rate of internalization and cancer-killing effects.

\section{APTAMER-MEDIATED COVID-19 PROPHYLACTIC VACCINE DEVELOPMENT AND DELIVERY}

Aptamers can be fabricated to bind with a specific target molecule and thus, can be an excellent and efficient candidate for the development of vaccines. However, these aptamers require a delivery system to make them reach and bind with the target site. Thus, aptameric viral vaccines, aptamer-mediated protein and DNA vaccines, as well as other novel vaccine with aptamers can also be beneficial as a potential vaccine candidate against the SARS-CoV-2 virus.

Several RNA aptamers have been synthesised in recent times to inhibit different viruses and have the potential of being engineered as potential vaccines to reduce viral loads in humans. Jung et al. identified that 
2'-fluoro-modified RNA aptamers can specifically bind with methyltransferase of dengue virus via SELEX technology, which is essential for the replication and translation of the viral genome, and acts directly on the structure of type-1 cap, 2'-O and N-7 methylation in viral RNA. In the study, the selected aptamer was truncated into an RNA sequence of 45-mer to bind with dengue viral methyltransferase serotype 2 and 3 for the effective inhibition of N-7 protein methylation activity. ${ }^{41}$ Likewise, Valencia-Resendiz et al. reported that RNA aptamer can be used to inhibit type 16 infection by human papillomavirus (HPV), which is responsible for $50 \%$ of cervical tumours in the world. In this study, high affinity Sc5c3 RNA aptamer was isolated that can bind specifically to HPV type 16 virus-like particles to inhibit the pseudovirus model. The study emphasized that the nuclease-resistant RNA $\mathrm{Sc} 5 \mathrm{c} 3$ aptamer can inhibit the infection by HPV in vitro and can also be effective in reducing the infection in vivo. ${ }^{74}$ Similarly, several other RNA, DNA and oligonucleotide aptamers are under extensive research and are being proven to be beneficial in the detection and development of antiviral vaccines. ${ }^{100}$ Aptamers synthesised to specifically bind SARS-CoV-2 can be delivered as vaccines through nanoencapsulation in a viral capsid. ${ }^{38}$ Various mechanisms through which aptamers can be engineered for the development of anti-SARS-CoV-2 vaccines is shown in Fig. 4.

\section{OUTLOOK}

As a typical characteristic of pandemics, it is anticipated that the transmission of COVID-19 will occur in multiple waves in successive months with high morbidity and mortality. It should be noted that the length of the peak outbreak of COVID-19 will last longer than most public health emergency diseases and

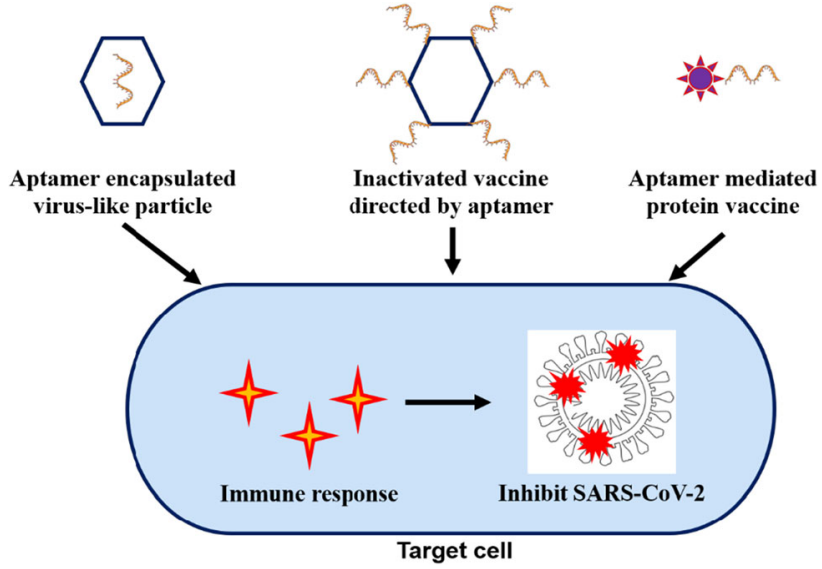

FIGURE 4. Proposed mechanism of action of aptamer-based virus and protein vaccines against SARS-CoV-2. will vary between communities and nations. In-depth epidemiological knowledge of COVID-19 is therefore critical in the development of cost-effective strategies for the control, surveillance, and diagnosis to limit the spread of the disease in the population. The macro impact of COVID-19 in nations across the globe is widely different due to the vast demographical differences in countries, hospital capacities, availability of tests, supply-chain capacities of protective equipment, and economic strengths. Also, the lack of sufficient rapid, affordable, and accurate detection of suspected COVID-19 cases has resulted in uncertainties in the estimated reproductive numbers $\left(\mathrm{R}_{\mathrm{o}}\right)$ and efficacy of public health measures. ${ }^{50}$

In order to mitigate the effect of the current pandemic and prevent future outbreaks, rapid targeted mass screening of people before or during symptomatic stages is inevitable. This will be crucial to test, trace, isolate and treat infected persons. In addition, community mass screening which is affordable will be critical in determining the percentage of asymptomatic patients. It will also help in identifying and isolating zoonotic hosts of the infectious disease. Historically, infrared scanners have been widely used in mass prescreening of suspected infected persons during severe outbreaks of infectious diseases and pandemics. Though helpful, infrared scanners are unable to effectively pre-screen COVID-19 asymptomatic persons at entry and exit points of geographical boundaries. This is evident in the high ratio of individuals estimated to not show any signs of fever for SARS-CoV-2 infection $(12.1 \%)$ relative to MERS-CoV $(2 \%)$ and SARS-CoV $(1 \%) .{ }^{95}$

Research advances into aptameric systems bode well with the fact that they can be engineered for the development of effective and affordable diagnostics, therapeutics and prophylactic vaccines for SARSCoV-2 and other infectious pathogens. Shedding of SARS-CoV-2 has been detected in various specimens such as nasal secretions, sputum, saliva, and faecal samples of infected persons. ${ }^{34}$ Although saliva specimens are easy to obtain, they contain low viral loads relative to nasal secretions, which makes it difficult for current molecular diagnostic test kits. However, aptameric probes have high specificity and low detection limits due to their unique three-dimensional structures and sequences. This allows for the development of realtime detection test kits for pathogens even in their latent state. ${ }^{1,2}$ Early diagnosis is inevitable for effective and early treatment of patients to avoid the severity of the infection. This will be very critical in saving lives in low resourced communities and nations. Also, owing to the bioavailability, high affinity, and specificity of aptameric ligands, novel therapeutic systems can be developed using aptamers for the treatment of COV- 
ID-19. The mode of entry for SARS-CoV-2 into host cells occurs through clathrin-mediated endocytosis which depends on the binding interaction between the receptor-binding domain (RBD, Arg319-Phe541) at the C-terminus of spike proteins of SARS-CoV-2 and the host cellular receptors, ACE2, along with S proteins priming by host cell transmembrane serine protease 2 (TMPRSS2). As such, future aptamer-based theranostic systems including prophylactic vaccines for COVID-19 can be developed based on either of the following mechanisms: (i) acting as antagonists by directly interacting with the RBD and SARS-CoV-2 proteins, namely; spike protein, envelope, membrane and nucleocapsid, in order to neutralise its infectivity; (ii) acting as antagonists by directly binding to ACE2 receptors to block $\mathrm{S}$ proteins; (iii) by acting as cargo for targeted delivery of other therapeutic agents; and (iv) acting as agonists to stimulate an appropriate immune response. In summary, there is an urgent need to develop safe innovative biomedical technologies to mitigate the dire impact of COVID-19 on public health worldwide.

\section{CONFLICT OF INTEREST}

Authors declare no conflict of interest.

\section{ETHICAL STANDARDS}

No human and animal studies were carried out by the authors of this article.

\section{REFERENCES}

${ }^{1}$ Acquah, C., Y. W. Chan, S. Pan, L. S. Yon, C. M. Ongkudon, H. Guo, and M. K. Danquah. Characterisation of aptamer-anchored poly(EDMA-co-GMA) monolith for high throughput affinity binding. Sci. Rep. 9:1-11, 2019.

${ }^{2}$ Acquah, C., M. K. Danquah, D. Agyei, C. K. S. Moy, A. Sidhu, and C. M. Ongkudon. Deploying aptameric sensing technology for rapid pandemic monitoring. Crit. Rev. Biotechnol. 36:1010-1022, 2015.

${ }^{3}$ Acquah, C., K. M. Danquah, J. L. S. Yon, A. Sidhu, and M. C. Ongkudon. A review on immobilised aptamers for high throughput biomolecular detection and screening. Anal. Chim. Acta 2015. https://doi.org/10.1016/j.aca.2015. 05.050.

${ }^{4}$ Afrasiabi, S., M. Pourhajibagher, R. Raoofian, M. Tabarzad, and A. Bahador. Therapeutic applications of nucleic acid aptamers in microbial infections. J. Biomed. Sci. 27:6, 2020.

${ }^{5}$ Ahn, D. G., I. J. Jeon, J. D. Kim, M. S. Song, S. R. Han, S. W. Lee, H. Jung, and J. W. Oh. RNA aptamer-based sensitive detection of SARS coronavirus nucleocapsid protein. Analyst 134:1896-1901, 2009.

${ }^{6}$ Alibolandi, M., M. Ramezani, F. Sadeghi, K. Abnous, and F. Hadizadeh. Epithelial cell adhesion molecule ap- tamer conjugated PEG-PLGA nanopolymersomes for targeted delivery of doxorubicin to human breast adenocarcinoma cell line in vitro. Int. J. Pharm. 479:241-251, 2015.

${ }^{7}$ BBC News. Coronavirus: Tiger at Bronx Zoo tests positive for Covid-19., 2020. https://www.bbc.com/news/wor ld-us-canada-52177586.

${ }^{8}$ Bar-On, Y. M., A. Flamholz, R. Phillips, and R. Milo. SARS-CoV-2 (COVID-19) by the numbers. Elife 9:e57309, 2020.

${ }^{9}$ Bellecave, P., M. L. Andreola, M. Ventura, L. TarragoLitvak, S. Litvak, and T. Astier-Gin. Selection of DNA aptamers that bind the RNA-dependent RNA polymerase of hepatitis C virus and inhibit Viral RNA synthesis in vitro. Oligonucleotides 13:455-463, 2003.

${ }^{10}$ Bhardwaj, J., N. Chaudhary, H. Kim, and J. Jang. Subtyping of influenza A H1N1 virus using a label-free electrochemical biosensor based on the DNA aptamer targeting the stem region of HA protein. Anal. Chim. Acta 1064:94-103, 2019.

${ }^{11}$ Bruno, J. G., A. M. Richarte, and T. Phillips. Preliminary development of a DNA aptamer-magnetic bead capture electrochemiluminescence sandwich assay for brain natriuretic peptide. Microchem. J. 115:32-38, 2014.

${ }^{12}$ Catuogno, S., M. T. Di Martino, S. Nuzzo, C. L. Esposito, P. Tassone, and V. de Franciscis. An antiBCMA RNA aptamer for miRNA intracellular delivery. Mol. Ther. Nucleic Acids 18:981-990, 2019.

${ }^{13}$ Chan, J. F. W., S. Yuan, K. H. Kok, K. K. W. To, H. Chu, J. Yang, F. Xing, J. Liu, C. C. Y. Yip, R. W. S. Poon, H. W. Tsoi, S. K. F. Lo, K. H. Chan, V. K. M. Poon, W. M. Chan, J. D. Ip, J. P. Cai, V. C. C. Cheng, H. Chen, C. K. M. Hui, and K. Y. Yuen. A familial cluster of pneumonia associated with the 2019 novel coronavirus indicating person-to-person transmission: a study of a family cluster. Lancet 395:514-523, 2020.

${ }^{14}$ Cho, S. J., H. M. Woo, K. S. Kim, J. W. Oh, and Y. J. Jeong. Novel system for detecting SARS coronavirus nucleocapsid protein using an ssDNA aptamer. J. Biosci. Bioeng. 112:535-540, 2011.

${ }^{15}$ Cui, L., H. Wang, Y. Ji, J. Yang, S. Xu, X. Huang, Z. Wang, L. Qin, P. Tien, X. Zhou, D. Guo, and Y. Chen. The nucleocapsid protein of coronaviruses acts as a viral suppressor of RNA silencing in mammalian cells. J. Virol. 89:9029-9043, 2015.

${ }^{16}$ Daei, P., M. Ramezanpour, K. Khanaki, M. Tabarzad, I. Nikokar, C. H. MojtabaHedayati, and A. Elmi. Aptamerbased targeted delivery of miRNA let-7d to gastric cancer cells as a novel anti-tumor therapeutic agent. Iran. J. Pharm. Res. 17:1537-1549, 2018.

${ }^{17}$ Dalirirad, S., and A. J. Steckl. Aptamer-based lateral flow assay for point of care cortisol detection in sweat. Sens. Actuators B Chem. 283:79-86, 2019.

${ }^{18}$ Dalirirad, S., and A. J. Steckl. Lateral flow assay using aptamer-based sensing for on-site detection of dopamine in urine. Anal. Biochem. 596:113637, 2020.

${ }^{19}$ de Haan, C. A. M., L. Kuo, P. S. Masters, H. Vennema, and P. J. M. Rottier. Coronavirus particle assembly: primary structure requirements of the membrane protein. $J$. Virol. 72:6838-6850, 1998.

${ }^{20}$ Dolai, S., and M. Tabib-Azar. Microfabricated nano-gap tunneling current zika virus sensors with single virus detection capabilities. IEEE Sens. J. 2020. https://doi.org/ $10.1109 /$ jsen.2020.2984172. 
${ }^{21}$ Du, L., Y. He, Y. Zhou, S. Liu, B.-J. Zheng, and S. Jiang. The spike protein of SARS-CoV: a target for vaccine and therapeutic development. Nat. Rev. Microbiol. 7:226-236, 2009.

${ }^{22}$ Duan, N., S. Wu, C. Zhu, X. Ma, Z. Wang, Y. Yu, and Y. Jiang. Dual-color upconversion fluorescence and aptamerfunctionalized magnetic nanoparticles-based bioassay for the simultaneous detection of Salmonella typhimurium and Staphylococcus aureus. Anal. Chim. Acta 723:1-6, 2012.

${ }^{23}$ Dutton, G. NSF-funded Smartphone COVID-19 Diagnostic Test Could Put Testing in the Hands of the Public., 2020. https://www.biospace.com/article/nsf-funded-smart phone-covid-19-dx-puts-testing-in-the-hands-of-the-publi $\mathrm{c} /$.

${ }^{24}$ Fehr, A. R., and S. Perlman. Coronaviruses: an overview of their replication and pathogenesis. Coronaviruses, New York: Springer, 2015, pp. 1-23.

${ }^{25}$ Forster, P., L. Forster, C. Renfrew, and M. Forster. Phylogenetic network analysis of SARS-CoV-2 genomes. Proc. Natl. Acad. Sci. 2020. https://doi.org/10.1073/pnas. 2004999117.

${ }^{26}$ Ganeshpurkar, A., G. Gutti, and S. K. Singh. RNA-dependent RNA polymerases and their emerging roles in antiviral therapy. Viral polymerases: structures, functions and roles as antiviral drug targets, Amsterdam: Elsevier, 2018, pp. 1-42.

${ }^{27}$ Gao, Y., X. Yu, B. Xue, F. Zhou, X. Wang, D. Yang, N. Liu, L. Xu, X. Fang, and H. Zhu. Inhibition of hepatitis C virus infection by DNA aptamer against NS2 protein. PLoS ONE 9:e90333, 2014.

${ }^{28}$ Ghinai, I., et al. First known person-to-person transmission of severe acute respiratory syndrome coronavirus 2 (SARS-CoV-2) in the USA. Lancet 395:1137-1144, 2020.

${ }^{29}$ Goldstein, S. A., J. M. Thornbrough, R. Zhang, B. K. Jha, Y. Li, R. Elliott, K. Quiroz-Figueroa, A. I. Chen, R. H. Silverman, and S. R. Weiss. Lineage A betacoronavirus NS2 proteins and the homologous torovirus berne ppla carboxy-terminal domain are phosphodiesterases that antagonize activation of RNase L. J. Virol. 91:e02201, 2017.

${ }^{30}$ Gopinath, S. C. B., and P. K. R. Kumar. Aptamers that bind to the hemagglutinin of the recent pandemic influenza virus $\mathrm{H} 1 \mathrm{~N} 1$ and efficiently inhibit agglutination. Acta Biomater. 9:8932-8941, 2013.

${ }^{31}$ Gorbalenya, A. E., S. C. Baker, R. S. Baric, R. J. de Groot, C. Drosten, A. A. Gulyaeva, B. L. Haagmans, C. Lauber, A. M. Leontovich, B. W. Neuman, D. Penzar, S. Perlman, L. L. M. Poon, D. V. Samborskiy, I. A. Sidorov, I. Sola, and J. Ziebuhr. The species severe acute respiratory syndrome-related coronavirus: classifying 2019$\mathrm{nCoV}$ and naming it SARS-CoV-2. Nat. Microbiol. 5:536544, 2020.

${ }^{32}$ Hahn, S. M. Coronavirus (COVID-19) Update: FDA expedites review of diagnostic tests to combat COVID-19, 2020. https://www.fda.gov/news-events/press-announcem ents/coronavirus-covid-19-update-fda-expedites-review-di agnostic-tests-combat-covid-19.

${ }^{33}$ Hamre, D., and J. J. Procknow. A new virus isolated from the human respiratory tract. Exp. Biol. Med. 121:190-193, 1966.

${ }^{34}$ Hindson, J. COVID-19: faecal-oral transmission? Nat. Rev. Gastroenterol. Hepatol. 2020. https://doi.org/10.103 8/s41575-020-0295-7.

${ }^{35}$ Huang, C., Y. Wang, X. Li, L. Ren, J. Zhao, Y. Hu, L. Zhang, G. Fan, J. Xu, X. Gu, Z. Cheng, T. Yu, J. Xia, Y.
Wei, W. Wu, X. Xie, W. Yin, H. Li, M. Liu, Y. Xiao, H. Gao, L. Guo, J. Xie, G. Wang, R. Jiang, Z. Gao, Q. Jin, J. Wang, and B. Cao. Clinical features of patients infected with 2019 novel coronavirus in Wuhan, China. Lancet 395:497-506, 2020.

${ }^{36}$ Ismail, S. I., and W. Alshaer. Therapeutic aptamers in discovery, preclinical and clinical stages. Adv. Drug Deliv. Rev. 134:51-64, 2018

${ }^{37}$ Jang, K. J., N. R. Lee, W. S. Yeo, Y. J. Jeong, and D. E. Kim. Isolation of inhibitory RNA aptamers against severe acute respiratory syndrome (SARS) coronavirus NTPase/ Helicase. Biochem. Biophys. Res. Commun. 366:738-744, 2008.

${ }^{38}$ Jeevanandam, J., K. Pal, and M. K. Danquah. Virus-like nanoparticles as a novel delivery tool in gene therapy. Biochimie 157:38-47, 2018.

${ }^{39} \mathrm{Ji}$, W., W. Wang, X. Zhao, J. Zai, and X. Li. Cross-species transmission of the newly identified coronavirus 2019nCoV. J. Med. Virol. 92:433-440, 2020.

${ }^{40}$ John Hopkins University, J. H. U. Racial Data Transparency., 2020. Accessed on 21 April 2020. https://corona virus.jhu.edu/data/racial-data-transparency.

${ }^{41}$ Jung, J. I., S. R. Han, and S.-W. Lee. Development of RNA aptamer that inhibits methyltransferase activity of dengue virus. Biotechnol. Lett. 40:315-324, 2018.

${ }^{42}$ Lau, S. K. P., P. Lee, A. K. L. Tsang, C. C. Y. Yip, H. Tse, R. A. Lee, L.-Y. So, Y.-L. Lau, K.-H. Chan, P. C. Y. Woo, and K.-Y. Yuen. Molecular epidemiology of human coronavirus OC43 reveals evolution of different genotypes over time and recent emergence of a novel genotype due to natural recombination. J. Virol. 85:11325-11337, 2011.

${ }^{43}$ Lau, S. K. P., P. C. Y. Woo, B. H. L. Wong, H. W. Tsoi, G. K. S. Woo, R. W. S. Poon, K. H. Chan, W. I. Wei, J. S. Malik Peiris, and K. Y. Yuen. Detection of severe acute respiratory syndrome (SARS) coronavirus nucleocapsid protein in SARS patients by enzyme-linked immunosorbent assay. J. Clin. Microbiol. 42:2884-2889, 2004.

${ }^{44}$ Lauer, S. A., K. H. Grantz, Q. Bi, F. K. Jones, Q. Zheng, H. R. Meredith, A. S. Azman, N. G. Reich, and J. Lessler. The incubation period of coronavirus disease 2019 (COVID-19) from publicly reported confirmed cases: estimation and application. Ann. Intern. Med. 2019. http s://doi.org/10.7326/m20-0504.

${ }^{45}$ Lee, C. H., Y. J. Lee, J. H. Kim, J. H. Lim, J.-H. Kim, W. Han, S.-H. Lee, G.-J. Noh, and S.-W. Lee. Inhibition of hepatitis $\mathrm{C}$ virus (HCV) replication by specific RNA aptamers against HCV NS5B RNA replicase. J. Virol. 87:7064-7074, 2013.

${ }^{46}$ Lee, C. Y.-P., R. T. P. Lin, L. Renia, and L. F. P. Ng. Serological approaches for COVID-19: epidemiologic perspective on surveillance and control. Front. Immunol. 11:879, 2020.

${ }^{47}$ Li, W., M. J. Moore, N. Vasilieva, J. Sui, S. K. Wong, M. A. Berne, M. Somasundaran, J. L. Sullivan, K. Luzuriaga, and T. C. Greenough. Angiotensin-converting enzyme 2 is a functional receptor for the SARS coronavirus. Nature 426:450-454, 2003.

${ }^{48}$ Li, B. J., Q. Tang, D. Cheng, C. Qin, F. Y. Xie, Q. Wei, J. Xu, Y. Liu, B. J. Zheng, M. C. Woodle, N. Zhong, and P. Y. Lu. Using siRNA in prophylactic and therapeutic regimens against SARS coronavirus in Rhesus macaque. Nat. Med. 11:944-951, 2005.

${ }^{49}$ Li, L., D. Xiang, S. Shigdar, W. Yang, Q. Li, J. Lin, K. Liu, and W. Duan. Epithelial cell adhesion molecule aptamer functionalized PLGA-lecithin-curcumin-PEG 
nanoparticles for targeted drug delivery to human colorectal adenocarcinoma cells. Int. J. Nanomed. 9:10831096, 2014.

${ }^{50}$ Liu, Y., A. A. Gayle, A. Wilder-Smith, and J. Rocklöv. The reproductive number of COVID-19 is higher compared to SARS coronavirus. J. Travel Med. 27:021, 2020.

${ }^{51}$ Liu, J., Q. Qin, X. Zhang, C. Li, Y. Yu, X. Huang, O. Mukama, L. Zeng, and S. Wang. Development of a novel lateral flow biosensor combined with aptamer-based Isolation: application for rapid detection of grouper nervous necrosis virus. Front. Microbiol. 11:886, 2020.

${ }^{52}$ Liu, F., C. Wang, Y. Gao, X. Li, F. Tian, Y. Zhang, M. Fu, P. Li, Y. Wang, and F. Wang. Current transport systems and clinical applications for small interfering RNA (siRNA) drugs. Mol. Diagn. Ther. 22:551-569, 2018.

${ }^{53}$ Liu, A., Y. Zhang, W. Chen, X. Wang, and F. Chen. Gold nanoparticle-based colorimetric detection of staphylococcal enterotoxin B using ssDNA aptamers. Eur. Food Res. Technol. 237:323-329, 2013.

${ }^{54}$ Low, S. Y., J. E. Hill, and J. Peccia. DNA aptamers bind specifically and selectively to $(1 \rightarrow 3)$ - $\beta$-d-glucans. Biochem. Biophys. Res. Commun. 378:701-705, 2009.

${ }^{55} \mathrm{Lu}, \mathrm{R}$., et al. Genomic characterisation and epidemiology of 2019 novel coronavirus: implications for virus origins and receptor binding. Lancet 395:565-574, 2020.

${ }^{56}$ McBride, R., M. Van Zyl, and B. C. Fielding. The coronavirus nucleocapsid is a multifunctional protein. Viruses 6:2991-3018, 2014

${ }^{57}$ Mojumdar, A., and J. Deka. Assaying the activity of helicases: an overview. Helicases from All Domains of Life, Amsterdam: Elsevier, 2018, pp. 235-246.

${ }^{58}$ Narayanan, K., A. Maeda, J. Maeda, and S. Makino. Characterization of the coronavirus $\mathrm{M}$ protein and nucleocapsid interaction in infected cells. J. Virol. 74:8127-8134, 2000.

${ }^{59}$ Naskalska, A., A. Dabrowska, A. Szczepanski, A. Milewska, K. P. Jasik, and K. Pyrc. Membrane protein of human coronavirus NL63 is responsible for interaction with the adhesion receptor. J. Virol. 93:e00355-e00369, 2019.

${ }^{60}$ Nitsche, A., A. Kurth, A. Dunkhorst, O. Pänke, H. Sielaff, W. Junge, D. Muth, F. Scheller, W. Stöcklein, C. Dahmen, G. Pauli, and A. Kage. One-step selection of vaccinia virus-binding DNA aptamers by MonoLEX. BMC Biotechnol. 7:48, 2007.

${ }^{61}$ Perrier, A., A. Bonnin, L. Desmarets, A. Danneels, A. Goffard, Y. Rouillé, J. Dubuisson, and S. Belouzard. The C-terminal domain of the MERS coronavirus M protein contains a trans-Golgi network localization signal. J. Biol. Chem. 294:14406-14421, 2019.

${ }^{62}$ Raj, V. S., H. Mou, S. L. Smits, D. H. W. Dekkers, M. A. Müller, R. Dijkman, D. Muth, J. A. A. Demmers, A. Zaki, R. A. M. Fouchier, V. Thiel, C. Drosten, P. J. M. Rottier, A. D. M. E. Osterhaus, B. J. Bosch, and B. L. Haagmans. Dipeptidyl peptidase 4 is a functional receptor for the emerging human coronavirus-EMC. Nature 495:251-254, 2013.

${ }^{63}$ Raj, V. S., A. D. M. E. Osterhaus, R. A. M. Fouchier, and B. L. Haagmans. MERS: emergence of a novel human coronavirus. Curr. Opin. Virol. 5:58-62, 2014.

${ }^{64}$ Roh, C., and S. K. Jo. Quantitative and sensitive detection of SARS coronavirus nucleocapsid protein using quantum dots-conjugated RNA aptamer on chip. J. Chem. Technol. Biotechnol. 86:1475-1479, 2011.
${ }^{65}$ Rotherham, L. S., C. Maserumule, K. Dheda, J. Theron, and M. Khati. Selection and application of ssDNA aptamers to detect active TB from sputum samples. PLoS ONE 7:e46862, 2012.

${ }^{66}$ Rouka, E., C. Hatzoglou, K. Gourgoulianis, and S. Zarogiannis. Antibody epitope and mimotope prediction of the viroporins M2 of the Influenza A virus, E of the Human SARS coronavirus and SH of the Respiratory Syncytial virus. Eur. Respir. J. 54:2387, 2019.

${ }^{67}$ Saravolac, E., J. Wong, and M. Cairns. Recent patents in antiviral siRNAs. Recent Pat. Antiinfect. Drug Discov. 5:44-57, 2010.

${ }^{68}$ Shum, K. T., and J. A. Tanner. Differential inhibitory activities and stabilisation of DNA aptamers against the SARS coronavirus helicase. ChemBioChem 9:3037-3045, 2008.

${ }^{69}$ Su, S., G. Wong, W. Shi, J. Liu, A. C. K. Lai, J. Zhou, W. Liu, Y. Bi, and G. F. Gao. Epidemiology, genetic recombination, and pathogenesis of coronaviruses. Trends Microbiol. 24:490-502, 2016.

${ }^{70}$ Tan, S. Y., C. Acquah, A. Sidhu, C. M. Ongkudon, L. S. Yon, and M. K. Danquah. SELEX modifications and bioanalytical techniques for aptamer-target binding characterization. Crit. Rev. Anal. Chem. 46:521-537, 2016.

${ }^{71}$ Tan, S. Y., C. Acquah, S. Y. Tan, C. M. Ongkudon, and M. K. Danquah. Characterisation of charge distribution and stability of aptamer-thrombin binding interaction. Process Biochem. 60:42-51, 2017.

${ }^{72}$ Tang, X. L., S. M. Wu, Y. Xie, N. Song, Q. Guan, C. Yuan, X. Zhou, and X. L. Zhang. Generation and application of ssDNA aptamers against glycolipid antigen ManLAM of Mycobacterium tuberculosis for TB diagnosis. J. Infect. 72:573-586, 2016.

${ }^{73}$ Tuerk, C., and L. Gold. Systematic evolution of ligands by exponential enrichment: RNA ligands to bacteriophage T4 DNA polymerase. Science 80(249):505-510, 1990.

${ }^{74}$ Valencia-Reséndiz, D. G., G. Palomino-Vizcaino, J. V. Tapia-Vieyra, M. L. Benítez-Hess, A. G. Leija-Montoya, and L. M. Alvarez-Salas. Inhibition of human papillomavirus type 16 infection using an RNA aptamer. Nucleic Acid Ther. 28:97-105, 2018.

${ }^{75}$ van Boheemen, S., M. de Graaf, C. Lauber, T. M. Bestebroer, V. S. Raj, A. M. Zaki, A. D. M. E. Osterhaus, B. L. Haagmans, A. E. Gorbalenya, and E. J. Snijder. Genomic characterization of a newly discovered coronavirus associated with acute respiratory distress syndrome in humans. MBio 3:e00473-e00482, 2012.

${ }^{76}$ van Doremalen, N., T. Bushmaker, D. H. Morris, M. G. Holbrook, A. Gamble, B. N. Williamson, A. Tamin, J. L. Harcourt, N. J. Thornburg, S. I. Gerber, J. O. LloydSmith, E. de Wit, and V. J. Munster. Aerosol and surface stability of SARS-CoV-2 as compared with SARS-CoV-1. N. Engl. J. Med. 2020. https://doi.org/10.1056/nejmc200 4973.

${ }^{77}$ van der Hoek, L., K. Pyrc, M. F. Jebbink, W. VermeulenOost, R. J. M. Berkhout, K. C. Wolthers, P. M. E. W. van Dillen, J. Kaandorp, J. Spaargaren, and B. Berkhout. Identification of a new human coronavirus. Nat. Med. 10:368-373, 2004.

${ }^{78}$ Van Nguyen, T. H., J. Lichiere, B. Canard, N. Papageorgiou, S. Attoumani, F. Ferron, and B. Coutard. Structure and oligomerization state of the C-terminal region of the Middle East respiratory syndrome coronavirus 
nucleoprotein. Acta Crystallogr. Sect. D Struct. Biol. 75:8-15, 2019

${ }^{79}$ Wahba, L., N. Jain, A. Z. Fire, M. J. Shoura, K. L. Artiles, M. J. McCoy, and D. E. Jeong. Identification of a pangolin niche for a 2019-nCoV-like coronavirus through an extensive meta-metagenomic search. bioRxiv 2020. $\mathrm{h}$ ttps://doi.org/10.1101/2020.02.08.939660.

${ }^{80}$ Wang, T., C. Chen, L. M. Larcher, R. A. Barrero, and R. N. Veedu. Three decades of nucleic acid aptamer technologies: lessons learned, progress and opportunities on aptamer development. Biotechnol. Adv. 37:28-50, 2019.

${ }^{81}$ Wang, C., W. Li, D. Drabek, N. M. A. Okba, R. van Haperen, A. D. M. E. Osterhaus, F. J. M. van Kuppeveld, B. L. Haagmans, F. Grosveld, and B.-J. Bosch. A human monoclonal antibody blocking SARS-CoV-2 infection. Nat. Commun. 11:2251, 2020.

${ }^{82}$ Weiss, S. R., and S. Navas-Martin. Coronavirus pathogenesis and the emerging pathogen severe acute respiratory syndrome coronavirus. Microbiol. Mol. Biol. Rev. 69:635-664, 2005.

${ }^{83}$ Westerbeck, J. W., and C. E. Machamer. The infectious bronchitis coronavirus envelope protein alters golgi $\mathrm{pH}$ to protect the spike protein and promote the release of infectious virus. J. Virol. 93:e00015-e00019, 2019.

${ }^{84}$ Woo, P. C. Y., Y. Huang, S. K. P. Lau, and K.-Y. Yuen. Coronavirus genomics and bioinformatics analysis. Viruses 2:1804-1820, 2010.

${ }^{85}$ Woo, P. C. Y., S. K. P. Lau, C.-M. Chu, K.-H. Chan, H.W. Tsoi, Y. Huang, B. H. L. Wong, R. W. S. Poon, J. J. Cai, W.-K. Luk, L. L. M. Poon, S. S. Y. Wong, Y. Guan, J. S. M. Peiris, and K.-Y. Yuen. Characterization and complete genome sequence of a novel coronavirus, coronavirus HKU1, from patients with pneumonia. J. Virol. 79:884-895, 2005.

${ }^{86}$ World Health Organisation, W.H.O. Coronavirus disease., 2020. https://www.who.int/emergencies/diseases/no vel-coronavirus-2019.

${ }^{87}$ World Health Organisation, W.H.O. Middle East respiratory syndrome coronavirus (MERS-CoV), 2020. https:// www.who.int/emergencies/mers-cov/en/.

${ }^{88}$ World Health Organisation, W.H.O. Cumulative Number of Reported Probable Cases of SARS., 2020. https://www. who.int/csr/sars/country/2003_07_11/en/.

${ }^{89}$ World Health Organisation, $\bar{W} \cdot \bar{H} . O$, Novel Coronavirus (2019-nCoV) Situation Report-10., 2020. https://www.wh o.int/docs/default-source/coronaviruse/situation-reports/ 20200130-sitrep-10-ncov.pdf.
${ }^{90}$ World Health Organisation, W.H.O. Virtual press conference on COVID-19, 11 March 2020. https://www.who. int/docs/default-source/\%0Acoronaviruse/transcripts/wh o-audioemergencies-coronavirus-press-conference-fullan d-fnal-11mar2020.pdf?sfvrsn $=$ cb432bb3_2.

${ }^{91}$ Worldometer. COVID-19 CORONĀVIRUS PANDEMIC., 2020. Accessed on 18th April, 2020. https://w ww.worldometers.info/coronavirus/.

${ }^{92}$ Xu, H., X. Mao, Q. Zeng, S. Wang, A. N. Kawde, and G. Liu. Aptamer-functionalized gold nanoparticles as probes in a dry-reagent strip biosensor for protein analysis. Anal. Chem. 81:669-675, 2009.

${ }^{93}$ Yamamoto, R., M. Katahira, S. Nishikawa, T. Baba, K. Taira, and P. K. R. Kumar. A novel RNA motif that binds efficiently and specifically to the Tat protein of HIV and inhibits the trans-activation by Tat of transcription in vitro and in vivo. Genes to Cells 5:371-388, 2000.

${ }^{94}$ Yang, D., and J. L. Leibowitz. The structure and functions of coronavirus genomic $3^{\prime}$ and $5^{\prime}$ ends. Virus Res. 206:120-133, 2015.

${ }^{95}$ Yuen, K. S., Z. W. Ye, S. Y. Fung, C. P. Chan, and D. Y. Jin. SARS-CoV-2 and COVID-19: the most important research questions. Cell Biosci. 10:40, 2020.

${ }^{96}$ Zhang, C., W. Zheng, X. Huang, E. W. Bell, X. Zhou, and Y. Zhang. Protein structure and sequence reanalysis of 2019-nCoV genome refutes snakes as its intermediate host and the unique similarity between its spike protein insertions and HIV-1. J. Proteome Res. 19:1351-1360, 2020.

${ }^{97}$ Zhou, J., H. Li, S. Li, J. Zaia, and J. J. Rossi. Novel dual inhibitory function aptamer-siRNA delivery system for HIV-1 therapy. Mol. Ther. 16:1481-1489, 2008.

${ }^{98}$ Zhou, J., and J. Rossi. Aptamers as targeted therapeutics: current potential and challenges. Nat. Rev. Drug Discov. 16:181-202, 2017.

${ }^{99}$ Zhu, N., D. Zhang, W. Wang, X. Li, B. Yang, J. Song, X. Zhao, B. Huang, W. Shi, R. Lu, P. Niu, F. Zhan, X. Ma, D. Wang, W. Xu, G. Wu, G. F. Gao, and W. Tan. A novel coronavirus from patients with pneumonia in China, 2019. N. Engl. J. Med. 382:727-733, 2020.

${ }^{100}$ Zou, X., J. Wu, J. Gu, L. Shen, and L. Mao. Application of aptamers in virus detection and antiviral therapy. Front. Microbiol. 10:1462, 2019.

Publisher's Note Springer Nature remains neutral with regard to jurisdictional claims in published maps and institutional affiliations. 